\title{
Mobility robustness optimization in self-organizing LTE femtocell networks
}

\author{
Wei Zheng ${ }^{1 *}$, Haijun Zhang ${ }^{1 *}$, Xiaoli Chu ${ }^{2}$ and Xiangming Wen ${ }^{1}$
}

\begin{abstract}
Femtocell is a promising solution for enhancing the indoor coverage and capacity in wireless networks. However, for the small size of femtocell and potentially frequent power on/off, existing handover schemes may not be reliable enough for femtocell networks. Moreover, improper handover parameters settings may lead to handover failures and unnecessary handovers, which make it necessary to enhance the mobility robustness for femtocells. In this article, we propose a gradient method and cost function-based mobility robustness optimization scheme for long term evolution (LTE) femtocell self-organizing networks. Moreover, signalling overhead of the scheme is analyzed. Simulation results show that the proposed scheme has a better performance than the fixed parameters method in terms of reduced the number of handover failures and unnecessary handovers with limited signalling modifications.
\end{abstract}

\section{Introduction}

As macrocells have limited indoor coverage, while above $50 \%$ of the voice services and $70 \%$ of the data traffics happen indoors [1], offloading the traffics from macrocells is badly needed. Femto base station (FBS), which is also known as HeNB [2], is a low power wireless access point that can meet the need. A femto user equipment (FUE) can save its power consumption for the smaller distance between transmitter and receiver in femtocell systems. Femtocell is more harmony to the environment due to the lower carbon emission. Furthermore, femtocells use the cable and DSL as the backhaul to access the service provider's network. As a result, it can improve the utility of the networks. Moreover, femtocell reduces the mobile operator's OPEX because of the user's self-deployment and self-configuration of FBS. However, the deployment of femtocell can also introduce technical challenges such as interference management and mobility management to long term evolution (LTE) and LTE-Advanced (LTE-A) networks.

In traditional mobility management schemes, the handover parameters are set by the mobile operator, which is inefficiency and inaccurate. Recently, mobility robustness optimization (MRO) as one of the usecases in the

\footnotetext{
*Correspondence: zhengweius@gmail.com; zhj@bupt.edu.cn

1 Beijing Key Laboratory of Network System Architecture and Convergence, Beijing University of Posts and Telecommunications, Beijing 100876, China Full list of author information is available at the end of the article
}

self-organization networks has been studied to reduce radio link failures (RLFs) and unnecessary handovers due to improper handover parameter settings [2]. However, traditional handover optimization is inappropriate for different characteristics in macrocell-femtocell hybrid deployment compared with those in macrocell due to the dynamic channel conditions and different mobility patterns. On one hand, the large number of femtocells makes it difficult to configure and maintains handover parameter optimization using existing schemes; on the other hand, since femtocell could be frequently turned on/off, channel conditions and neighboring cell list change frequently. To the best of authors' knowledge, there are few studies focusing on mobility robustness optimization in femtocell networks.

There are a lot of researches concerning the handover optimization in LTE macrocells. In [3], a cost function based handover parameter optimization scheme incorporating cell load, UE's velocity and service type, is proposed for 3GPP LTE macrocells. In [4], admission control strategy and handover self-optimization are considered to optimize the handover performance. Joint hysteresis and time to trigger (TTT) optimization scheme is investigated in [5] to reduce handover failures. Most of these studies optimize the handover parameters, such as hysteresis and TTT, based on self-optimization techniques.

MRO in macrocells has been extensively studied. In [6], hysteresis adapting based MRO scheme is proposed

\section{Springer}

(c) 2013 Zheng et al: licensee Springer. This is an Open Access article distributed under the terms of the Creative Commons Attribution License (http://creativecommons.org/licenses/by/2.0), which permits unrestricted use, distribution, and reproduction in any medium, provided the original work is properly cited. 
considering different UE velocities. The conflict between Mobility Load Balancing and MRO in handover parameters adjusting is solved in [7]. Authors in [8] investigate the inter radio access technologies (inter-RAT) mobility robustness optimization between LTE and 3G/2G mobile systems.

Different from the mobility robustness optimization in macrocells, the frequent switching on/off of them require robustness of the femtocell handover optimization, and traditional handover optimization may not be feasible for the femtocell deployments. And a lot of works have studied mobility management in femtocells, aiming to optimize neighbor cell list and reduce handover signalling cost for femtocells [9,10]. In [11-13], interference and cell selection are managed using handover in femtocells. In [14], the authors propose a simple but effective method to access control and mobility management by rejecting the non-CSG user equipment (UE) coming close to the femtocell by using the CSG member list to reduce unnecessary handover in femtocell-macrocell coexisting scenarios. A novel handover decision algorithm using the combination of received signal strengths of the source cell and target cell is proposed to obtain a better system performance [15]. Mobility enhanced scheme is introduced in [16] and signalling analysis for femtocell mobility is presented in [17]. However, MRO in two-tier femtocell-macrocell networks receives little attention.

In this article, we develop a handover parameter adjusting-based mobility robustness optimization scheme, which aims to reduce unnecessary handovers and RLFs caused by too late handover, too early handover, or wrong handover in open access femtocells. In order to realize the mobility robustness optimization, a cost function incorporating the unnecessary handovers and wrong handovers is introduced, and then a MRO scheme based on gradient algorithm $[18,19]$ is proposed for femtocell networks. Finally, performance of the proposed algorithm is evaluated by extensive simulations.

The rest of the article is organized as follows. Section 2 introduces the handover procedure, handover parameters and system model. In Section 3, gradient method based MRO is proposed with an analysis of signalling overhead and complexity. The simulation results are provided in Section 4. Finally, Section 5 concludes the article.

\section{Handover procedure and system model}

In this section, basic handover procedure and related parameters of femtocell handover are introduced, then RLF scenarios caused by too late handover, Too early handover, wrong handover, and unnecessary handover are described respectively.

\subsection{LTE femtocell system}

The standard femtocells coexisting with macrocells in LTE/LTE-A have been discussed in the Femto Forum, 3GPP and NGMN Alliance. Some mobility enhancing schemes have been considered in LTE/LTE-A femtocell networks [16]. The reference LTE/LTE-A femtocell architecture is shown in Figure 1, which supports X2-based $\mathrm{HO}$ between HeNB and S5 procedures in case of local IP access (LIPA) [20].

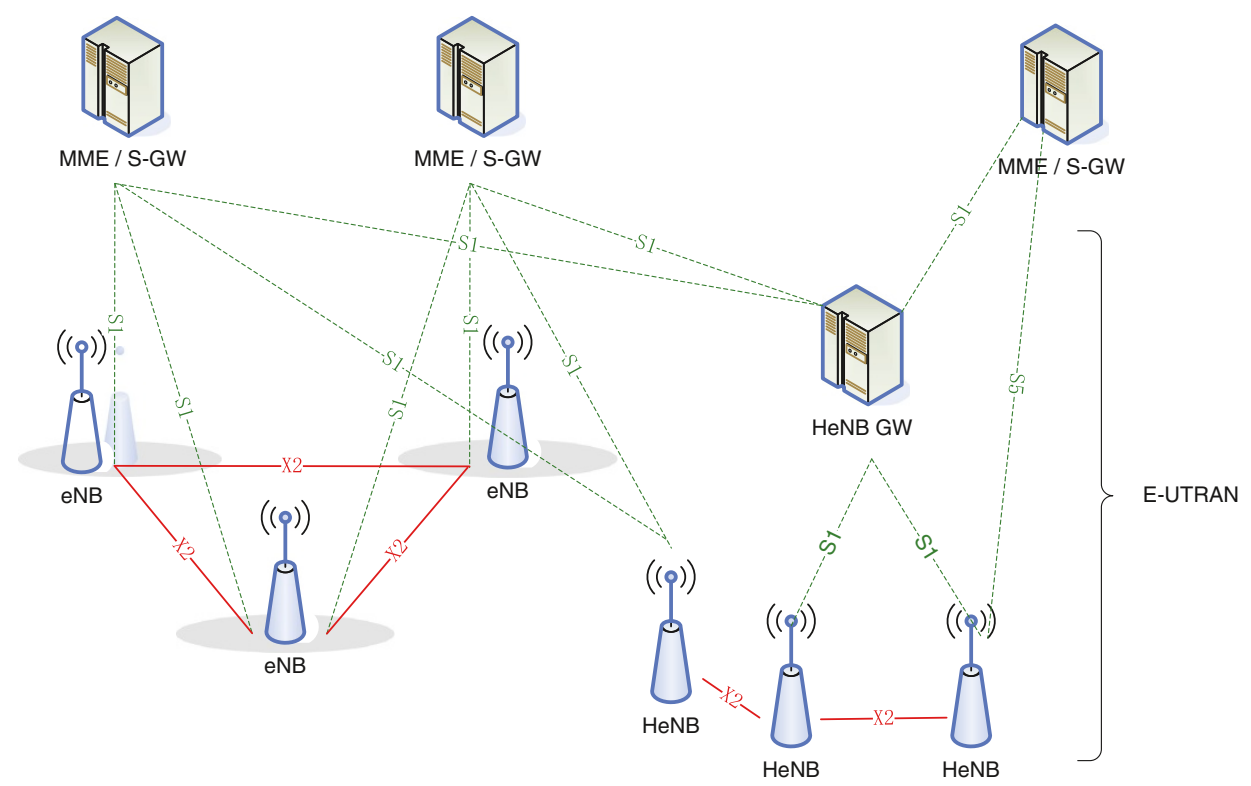

Figure 1 Overall E-UTRAN architecture with deployed HeNB GW. 

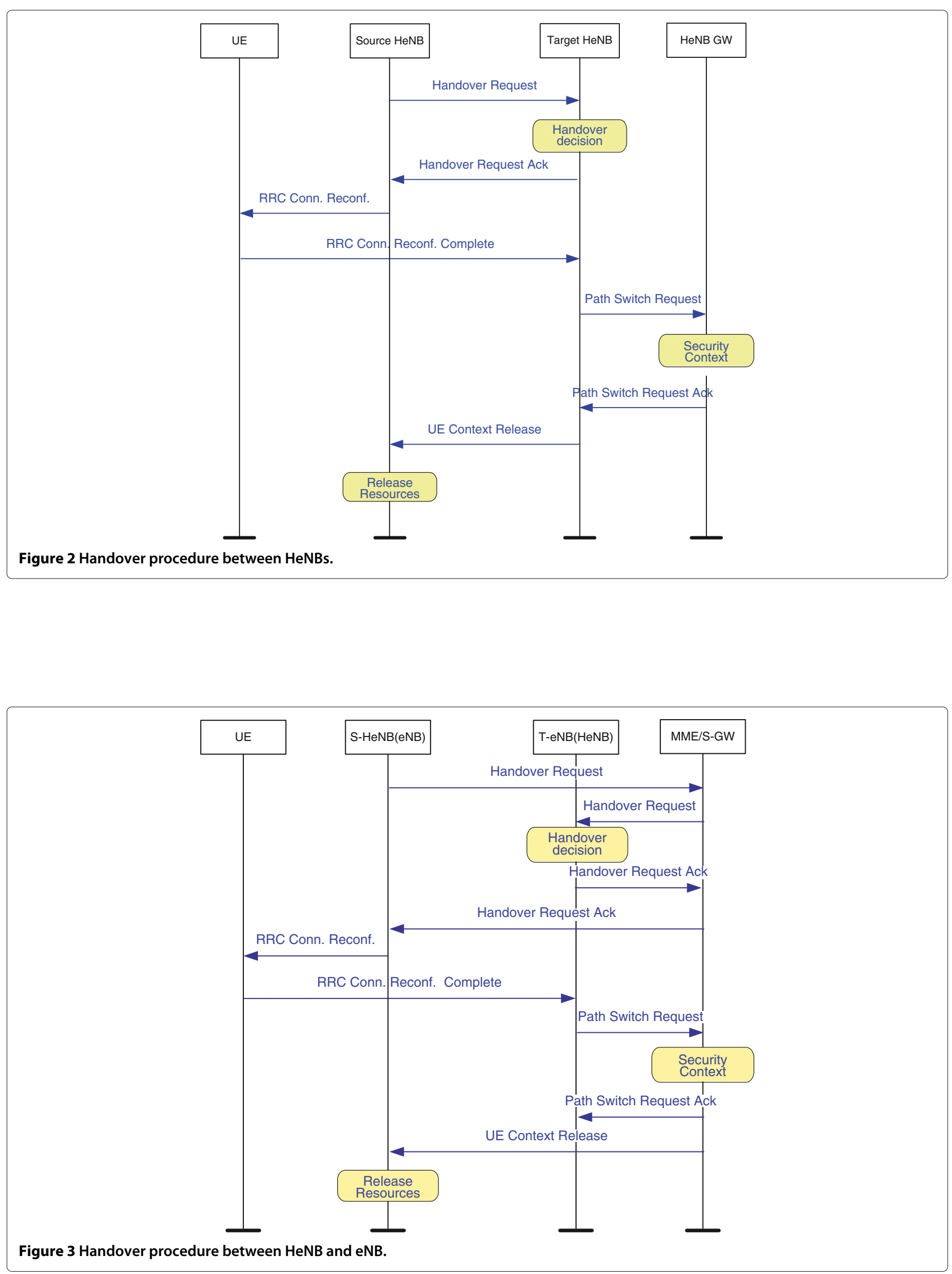


\subsection{Handover procedures and parameters}

Since X2 interface is introduced in Figure 1, which is different from the early version of E-UTRAN network architecture [21], HeNB related handover procedure should be revised in both HeNB-HeNB handover and eNB-HeNB handover. Here we will present handover call flow based on the current E-UTRAN architecture [20] as illustrated in Figures 2 and 3. Figure 2 shows the handover procedures between HeNBs and Figure 3 presents the handover flow between eNB and HeNB [16].

Handover in LTE/LTE-A femtocells is assumed as network-controlled hard handover with the assistance of UE $[7,22]$. Handover procedure in LTE femtocells can be divided into four phases: handover measurement, measurement report, handover decision, handover execution. FUE periodically measures the reference signal received powers (RSRPs) of the serving cell and neighbor cells according to the measurement configuration and neighbor cell list sent by FBS. According to [23], if the entering condition of A3 event (neighbor cell is better than serving cell) in (1) is satisfied and lasts for a duration of TTT, then the A3 event will be triggered. After receiving the report from FUE, the serving cell will handover the FUE to the target cell. Otherwise, the FUE will leave A3 event if the leaving condition in (2) is satisfied.

$$
\begin{aligned}
& \mathrm{RSRP}_{t}+\mathrm{CIO}_{t}-\mathrm{Hys}>\mathrm{RSRP}_{s}+\mathrm{CIO}_{s}+\text { Off } \\
& \mathrm{RSRP}_{t}+\mathrm{CIO}_{t}+\text { Hys }<\mathrm{RSRP}_{s}+\mathrm{CIO}_{s}+\text { Off }
\end{aligned}
$$

where $\operatorname{RSRP}_{s}$ and $\mathrm{RSRP}_{t}$ are the signal strengths of the serving cell and the target cell measured by UE, respectively, $\mathrm{CIO}_{s}$ and the $\mathrm{CIO}_{t}$ are the cell individual offset (CIO) of the serving cell and the target cell, respectively, Hys is the hysteresis value of A3 event, and Off is the offset parameter of A3 event. Given the value of Hys and Off, UE tends to handover to the cell whose CIO plus RSRP is higher.

\subsection{Definition and detection of MRO events}

Inappropriate handover parameters can lead to handover failures. Three types of RLF related to MRO are defined

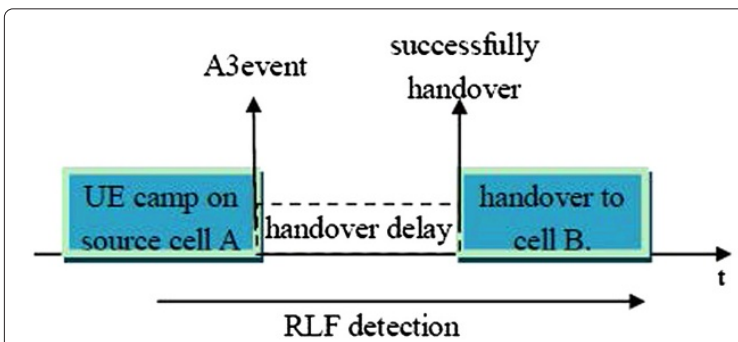

(a) Regular Handover

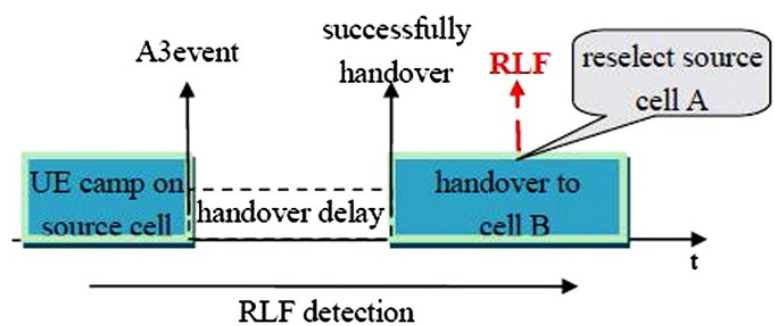

(c) Too Early Handover

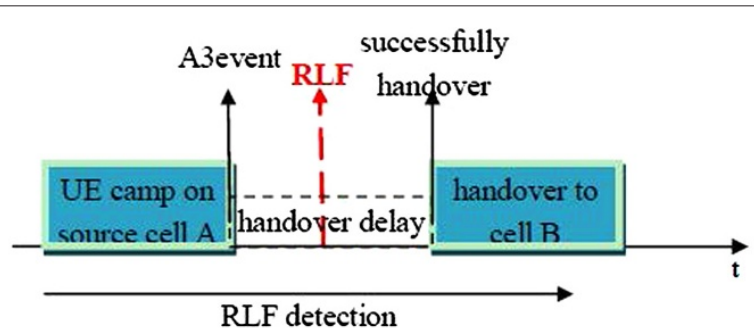

(b) Too Late Handover

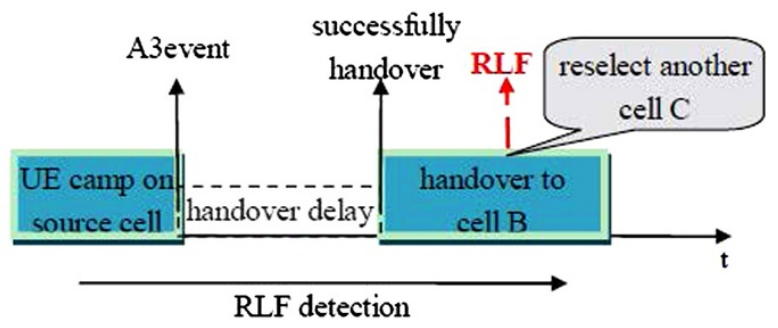

(d) Wrong Handover

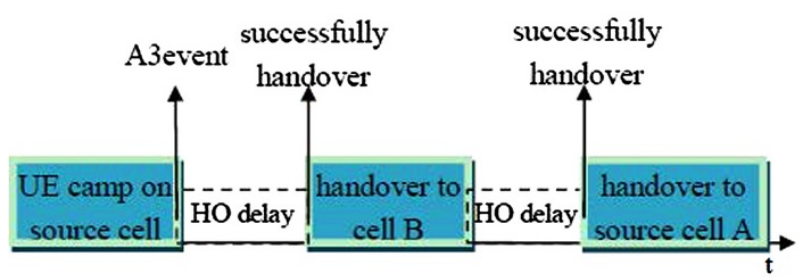

(e) Ping-Pong Handover

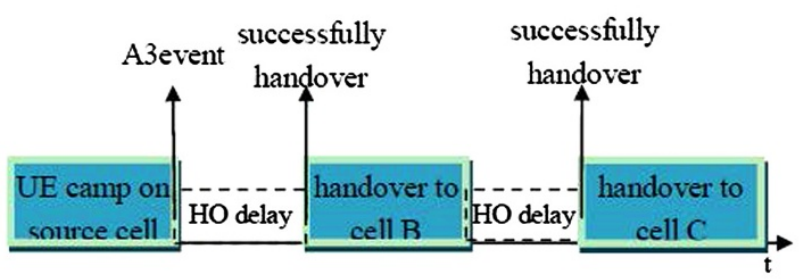

(f) Continuous Handover

Figure 4 Basic scenarios of MRO. 
in LTE SON: too late handover, too early handover, and wrong handover. Two types of unnecessary handover are defined in MRO: ping-pong handover and continuous handover. The characteristics of the mobility related unsuccessful handovers and the unnecessary handovers are described in Figure 4 [2]:

(b) Too late handover: RLF occurs in serving cell before handover or during the handover procedure, then UE reconnect to the target cell (different from the serving cell).

(c) Too early handover: RLF occurs shortly after a successful handover to the target cell, and then UE reconnect to the serving cell.

(d) Wrong handover: RLF occurs shortly after a successful handover to the target cell, and then UE reconnect to another cell (neither the serving cell nor the target cell).

(e) Ping-pong handover: handover to the serving cell from the target cell shortly after a successful handover to the target cell.

(f) Continuous handover: handover to another cell (neither the serving cell nor the target cell) shortly after a successful handover to the target cell.

The proposed procedure of RLF detection related to handover and unnecessary handover is shown in Algorithm 1.

In Algorithm 1, Timer_UE_ID is the timer for UE, RLF_UE_ID is Cell ID of UE who undergos RLF, Last_Visited_Cell_ID is the Cell ID the UE lase visited, and Reconnected_Cell_ID is the Cell ID the UE reconnected after encountering RLF. The RLF event is detected and reported by UE once the RLF occurs, and then Timer_UE_ID, RLF_UE_ID, Last_Visited_Cell_ID, together with Reconnected_Cell_ID, are report to the FBS/MBS, and are finally collected by the SON module where the $\mathrm{MRO}$ algorithm is implemented.

\section{Gradient method based femtocell MRO}

There are many handover parameters in femtocell MRO. Without loss of generality, we choose the CIO as the handover parameter to optimize in this article.

\subsection{Cost function}

In order to reduce RLFs and unnecessary handovers in femtocells, we propose a cost function based algorithm, which is defined as follows:

$$
C=\sum_{i=1}^{5} \alpha_{i} N_{i}
$$

where $N_{1}, N_{2}, N_{3}, N_{4}$, and $N_{5}$ denote the numbers of pingpong handover, continuous handover, too late handover, too early handover and wrong handover, respectively, and

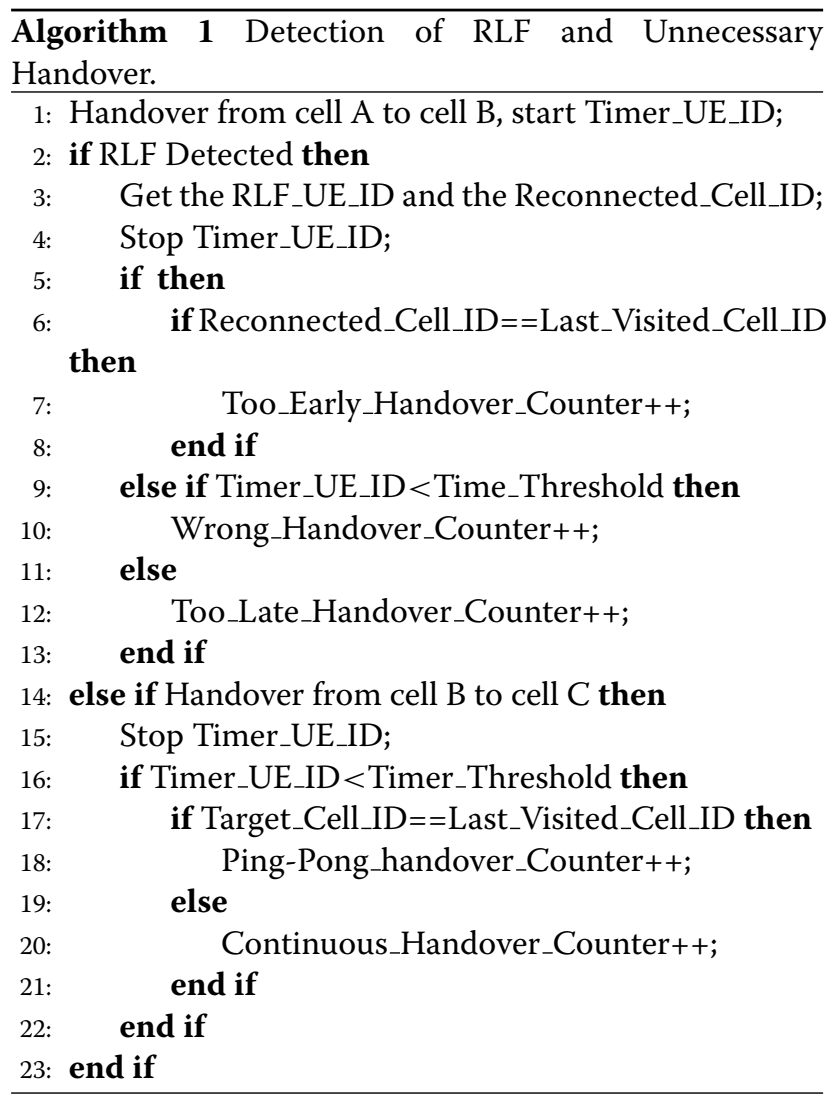

$\alpha_{i}$ denotes the weight factor of $N_{i}$. The value of $N_{i}$ is determined by Algorithm 1.

\subsection{Gradient method based MRO}

In this section, we introduce the gradient algorithm $[18,19,24]$ into femtocell MRO.

The optimization algorithm to be used in the minimization of the cost function is derived from first principles for one single parameter. It is easy to extend the derivation to the case of several parameters. Consider the general case of a cost function $C$ to be minimized with respect to a parameter denoted by $w$. Let $w^{*}$ be the value of $w$ which minimizes $C$. Evaluating $C\left(w^{*}\right)$ using the Taylor series expansion about any value of $w$ gives [19],

$$
C\left(w^{*}\right)=C(w)+\left(w^{*}-w\right) C^{\prime}(w)+\frac{\left(w^{*}-w\right)^{2}}{2} C^{\prime \prime}(w)
$$

As $C\left(w^{*}\right)$ is a minimum point of $C$, then differentiating (4) with respect to $w^{*}$ and letting the result equal 0 gives:

$$
w^{*}=w-\frac{C^{\prime}(w)}{C^{\prime \prime}(w)}
$$

Consider a small change $\delta w(>0)$ in the value of the parameter $w$ to give a new parameter value $w+\delta w$. The value of the cost function can then be approximated as, 


$$
C(w+\delta w)=C(w)+\delta w C^{\prime}(w)+\frac{\delta w^{2}}{2} C^{\prime \prime}(w)
$$

Consider a decrease in the value of $w$ by $\delta w>0$ to give a new parameter value $w-\delta w$. Once again the value of the cost function for this parameter value can be expressed as:

$$
C(w-\delta w)=C(w)-\delta w C^{\prime}(w)+\frac{\delta w^{2}}{2} C^{\prime \prime}(w)
$$

Solving (6) and (7) for $C^{\prime \prime}(w)$ and $C^{\prime}(w)$, we have,

$$
\begin{aligned}
& C^{\prime \prime}(w)=\frac{C(w+\delta w)+C(w-\delta w)-2 C(w)}{\delta w^{2}} \\
& C^{\prime}(w)=\frac{C(w+\delta w)-C(w-\delta w)}{2 \delta w}
\end{aligned}
$$

Substituting (8) and (9) into (5), we get

$$
w^{*}=w-\frac{\delta w(C(w+\delta w)-C(w-\delta w))}{2(C(w+\delta w)+C(w-\delta w)-2 C(w))}
$$

Based on the above gradient algorithm, the pseudo code of the MRO algorithm is described in Algorithm 2.

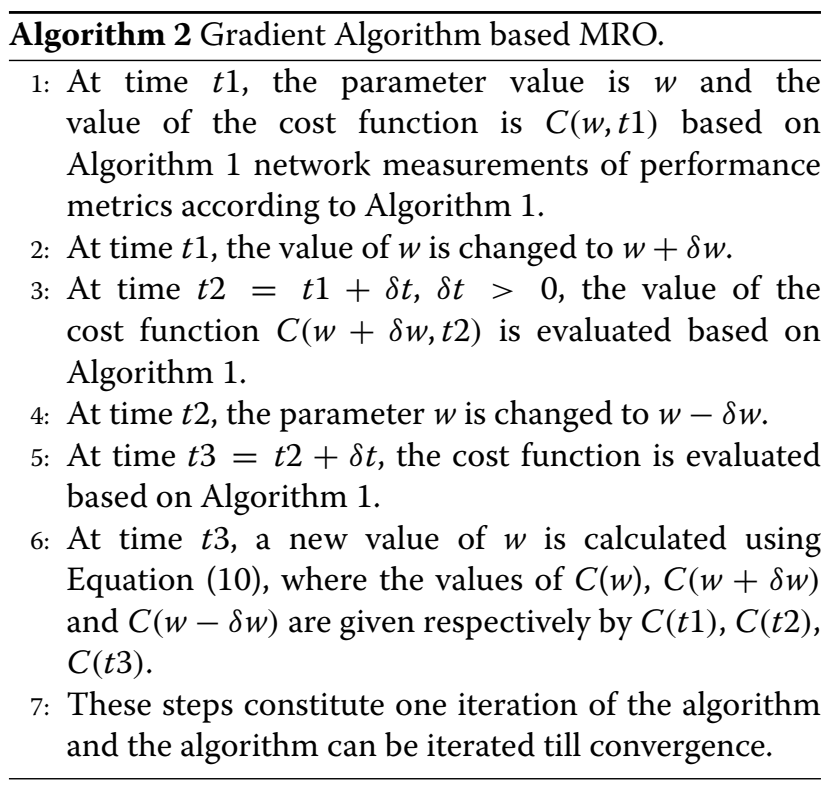

\subsection{Signalling overhead analysis}

For the gradient method used in Algorithm 2, the number of iterations required to minimize the cost function $C$ is upper bounded by [25]

$$
\frac{C\left(w_{0}\right)-C^{*}}{\gamma}+\log _{2}\left(\log _{2}\left(\frac{\varepsilon_{0}}{\varepsilon}\right)\right)
$$

\begin{tabular}{|c|c|}
\hline Parameter & Value \\
\hline MBS number & 1 \\
\hline FBS number & 20 \\
\hline Femtocell layout & $\begin{array}{l}\text { A modified dual strip model } \\
\text { (five apartments in a row) }\end{array}$ \\
\hline Macrocell radius & $577 m$ \\
\hline Femtocell radius & $6 m$ \\
\hline Carrier frequency & $2 \mathrm{GHz}$ \\
\hline System bandwidth & $10 \mathrm{MHz}$ \\
\hline \multirow[t]{2}{*}{ Antenna gain } & UE: 0 dBi, MBS: 15 dBi \\
\hline & FBS: omni-direction 5 dBi [27] \\
\hline \multirow[t]{2}{*}{ Log-normal shadowing } & Standard deviation FBS-UE $10 \mathrm{~dB}$ \\
\hline & Standard deviation MBS-UE 8 dB [27] \\
\hline MBS transmitting power & $46 \mathrm{dBm}$ \\
\hline FBS transmitting power & $20 \mathrm{dBm}$ \\
\hline UE mobility model & Random way-point model [26] \\
\hline MBS UE velocity & Uniform $(0,30) \mathrm{km} / \mathrm{h}$ \\
\hline FBS UE velocity & Uniform $(0,5.4) \mathrm{km} / \mathrm{h}$ \\
\hline \multicolumn{2}{|l|}{ UE distribution and } \\
\hline \multirow[t]{4}{*}{ mobility range } & indoor UE: \\
\hline & within FBS coverage area \\
\hline & outdoor UE: \\
\hline & within in the MBS coverage area \\
\hline \multirow[t]{2}{*}{ Traffic model } & indoor UE: Full queue traffic \\
\hline & outdoor UE: voice traffic \\
\hline Outdoor UE to MBS & $P L(d B)=15.3+37.6 \operatorname{lgR}, R$ in $m[27]$ \\
\hline Indoor UE to MBS & $\mathrm{PL}(\mathrm{dB})=15.3+37.6 \lg R+\operatorname{Low}[27]$ \\
\hline \multicolumn{2}{|l|}{ UE to FBS (UE is inside the } \\
\hline same apt as FBS) & $P L(d B)=38.46+20 \lg R+q^{*} \operatorname{Liw}[27]$ \\
\hline \multicolumn{2}{|l|}{ Indoor UE to FBS (UE inside } \\
\hline \multirow[t]{2}{*}{ a different apt as FBS) } & $P L(d B)=\max (15.3+37.6 \lg R$ \\
\hline & $38.46+20 \lg R)+q^{*} \operatorname{Liw}+p^{*} \operatorname{Low}[27]$ \\
\hline Sampling time & $10 \mathrm{~ms}$ \\
\hline Minimum coupling losses & $70 \mathrm{~dB}$ \\
\hline Out of Sync threshold & $-4.5 \mathrm{~dB}$ \\
\hline In Sync threshold & $-2.1 \mathrm{~dB}$ \\
\hline
\end{tabular}

where $w_{0}$ is the initial value of $w ; C^{*}$ is the minimum value of $C ; \gamma$ is the smallest decrease of $C$ in each iteration; $\varepsilon_{0}$
Table 1 Simulation parameters

is a constant depending on $w_{0}$; and $\varepsilon$ is the convergence tolerance.

For the detection of RLF and unnecessary handover in Algorithm 1, only three decision processes are needed to detect the handover event (e.g., lines 2, 5, 6 in Algorithm 1 to detect the too early handover). Moreover, the factors for detection in Algorithm 1, Timer_UE_ID, RLF_UE_ID, Last_Visited_Cell_ID, together with Reconnected_Cell_ID, are reported to the FBS/MBS, 


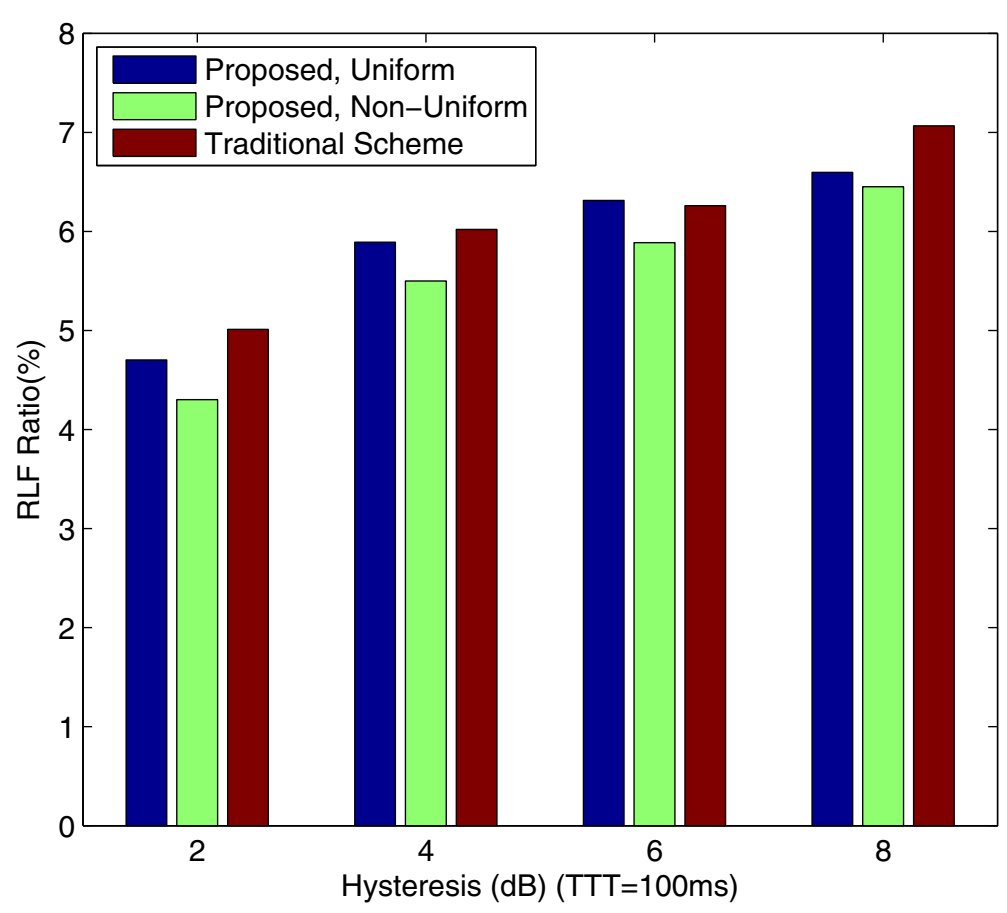

Figure $5 \mathrm{RLF}$ ratio versus hysteresis $(\mathrm{TTT}=100 \mathrm{~ms})$.

when a RLF event is detected. A similar signalling overhead is needed for unnecessary handover detection. Therefore, both Algorithms 1 and 2 can be implemented with little modifications of existing LTE/LTE-A handover protocol.

\section{Performance evaluation}

The gradient based MRO algorithm proposed in this article is evaluated in a femtocell network by simulation. A macrocell and $F$ femtocells coexisting scenario for the simulation is considered, and $F$ is assumed to be 20 . The

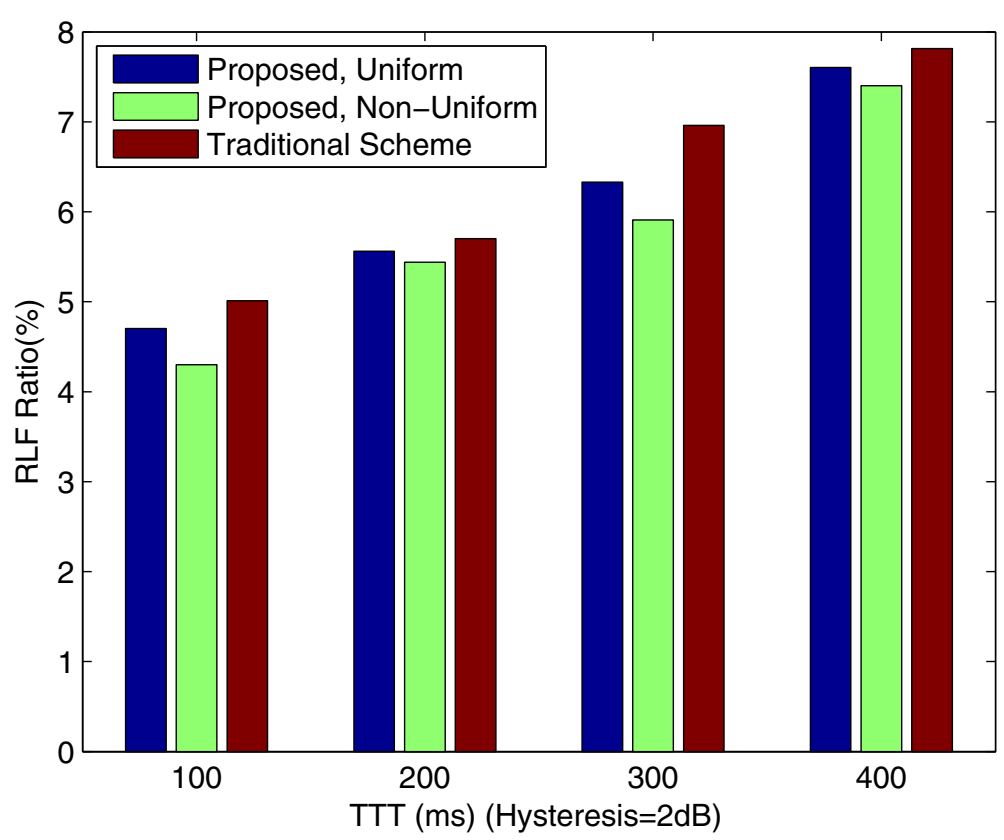

Figure 6 RLF ratio versus TTT (Hysteresis $=2 \mathrm{~dB}$ ). 
random way-point model [26] is used as UE mobility model. A UE's location is generated by a random destination and a random sample velocity with a sightline. Once reaching the destination, the UE stays for a random period of time. The macro UE (MUE) and FUE are assigned with different maximum velocity limits. The simulation parameters such as path loss, shadowing, and fading models, are given in Table 1.

For the purpose of examining the impact of weight factors, two settings of weighting factors $\alpha_{i}$, which are named as uniform $\mathrm{MRO}$ and non-uniform MRO, respectively, are evaluated in the simulation. For uniform weighting, $\alpha_{i}=$ 1 , for $i=1, \ldots, 5$. For Non-Uniform weighting, $\alpha_{i}=1$, for $i=1,2,3$, and $\alpha_{i}=3$, for $i=4,5$. To verify the effectiveness of the algorithms proposed, the Traditional Scheme, which uses fixed values of handover parameters, is compared with the proposed MRO algorithms. The RLF ratio is defined as the ratio of the number of RLFs caused by too late handover, too early handover, and wrong handover to the total handover attempts. Unnecessary handover ratio is defined as the proportion of ping-pong handover and continuous handover in the total handover attempts. Figures 5, 6, 7, and 8 show the comparison of the Traditional Scheme with the proposed gradient based MRO for different values of hysteresis and TTT.

As can be seen from Figure 5, the RLF rate increases as the hysteresis increases. This is because when the threshold of the handover parameter (hysteresis) increases, FUEs tend to stay in the camping femtocell, instead of handover to other femtocells, which may have better signals. Therefore, a bigger hysteresis results in less handover attempts, but the too late handovers may still happens with Algorithm 1, resulting in increased RLF ratio. The number of too early handovers increases as the hysteresis/TTT increases, but the trend of RLF ratio does not change for the small number of too early handover in total RLFs. It can be seen from Figure 5 that the gradient based mobility robustness optimization has a better performance than traditional scheme in terms of RLF ratio. Since Non-Uniform MRO has a heavy weighting in Too Late Handovers, the proposed non-uniform scheme results in a lower RLF ratio.

In Figure 6, as the value of TTT increases, the RLF rate increases. This is because when the value of TTT increases, FUEs tend not to handover to other femtocells due to the extended observation window time. Therefore, more Too Late Handovers happen in Algorithm 1, which results in higher RLF ratio. The proposed schemes outperform the traditional scheme, and non-uniform MRO has a better performance than the Uniform one.

Figure 7 illustrates the unnecessary handover ratio of all schemes considered. As can be seen in Figure 7, unnecessary handover ratio decreases as hysteresis increases, because when the threshold of handover decision decreases, Too early handovers, ping-pong handovers, and continuous handovers are more likely to happen in Algorithm 1. Similar observations can be made in Figure 8, where unnecessary handovers occur because the observation window time is longer due to the shorter TTT. In both Figures 7 and 8, Uniform weighting factors has better performance than Non-Uniform ones, because unnecessary handover has a lower weighting factor in Non-Uniform

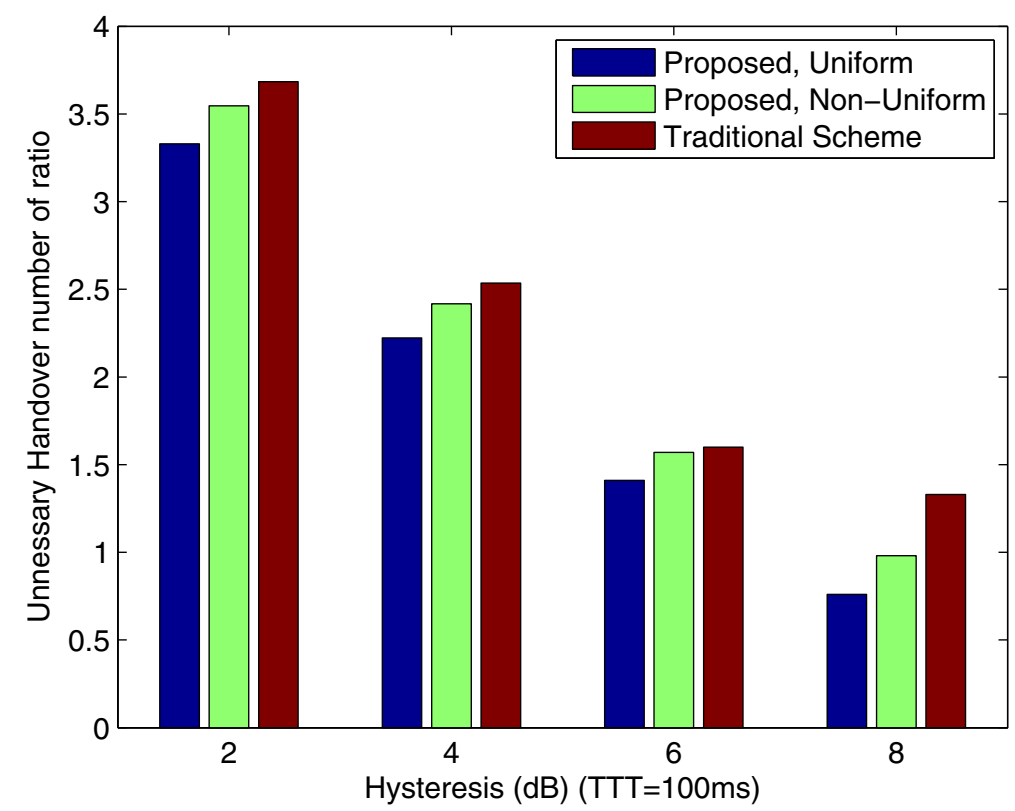

Figure 7 Unnecessary handover ratio versus hysteresis (TTT $=100 \mathrm{~ms}$ ). 


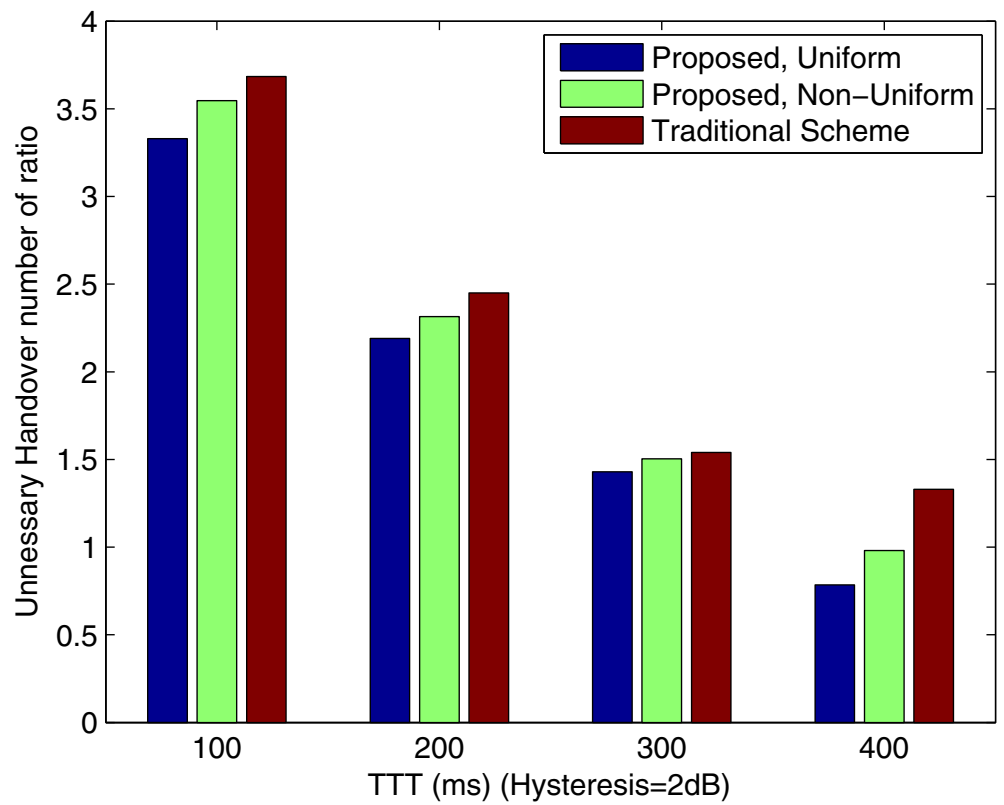

Figure 8 Unnecessary handover ratio versus TTT (Hysteresis $=2 \mathrm{~dB}$ ).

schemes. The proposed algorithm obtains a good tradeoff between unnecessary handovers and unsuccessful handovers through adjusting weighting factors. Since RLF is more intolerant for uses compared with unnecessary handover, the non-uniform weighting scheme more preferred.

\section{Conclusion}

In this article, a gradient based MRO scheme together with a detection algorithm of RLF and Unnecessary Handover is proposed in self-organizing LTE/LTE-A femtocell networks. After the successful detection using Algorithms 1 and 2 uses a gradient method to reduce the RLF and Unnecessary Handovers based on a cost function calculated by Algorithm 1. Simulation results have shown that the proposed scheme can achieve a reduction of RLF ratio and unnecessary handover Ratio with little handover signalling modifications.

\section{Competing interests}

The authors declare that they have no competing interests.

\section{Acknowledgements}

This study was supported by the National Natural Science Foundation of China (61 101109), the Youth Research and Innovation Project of Beijing University of Posts and Telecommunications, the Co-building Project of Beijing Municipal Education Commission, and the National S\&T Major Project of China (Nos. 2010ZX03003-001-01 and 2011ZX03003-002-01).

\section{Author details}

${ }^{1}$ Beijing Key Laboratory of Network System Architecture and Convergence, Beijing University of Posts and Telecommunications, Beijing 100876, China.

${ }^{2}$ Department of Electronic and Electrical Engineering, University of Sheffield, Sheffield, S1 3JD, UK.
Received: 20 September 2012 Accepted: 17 December 2012 Published: 12 February 2013

\section{References}

1. D Lopez-Perez, A Valcarce, $G$ de la Roche, J Zhang, OFDMA femtocells: a roadmap on interference avoidance. IEEE Commun. Mag. 47(9), 41-48 (2009)

2. 3GPP: Self-configuring and self-optimizing network (SON) use cases and solutions (2011)

3. DW Lee, GT Gil, DH Kim, A cost-based adaptive handover hysteresis scheme to minimize the handover failure rate in 3GPP LTE system. EURASIP J. Wirel. Commun. 2010, 6:1-6:7 (2010)

4. B Sas, K Spaey, I Balan, K Zetterberg, R Litjens, in Proc. IEEE VTC Spring. Self-optimisation of admission control and handover parameters in LTE, (Budapest, Hungary, 2011), pp. 1-6

5. T Jansen, I Balan, J Turk, I Moerman, T Kurner, in Proc. IEEE VTC Fall. Handover parameter optimization in LTE self-organizing networks, (Ottawa, ON, Canada, 2010), pp. 1-5

6. Z Wei, in Proc. IEEE WCSP. Mobility robustness optimization based on UE mobility for LTE system, (Suzhou, China, 2010), pp. 1-5

7. Z Liu, P Hong, K Xue, M Peng, in Proc. IEEE GLOBECOM. Conflict avoidance between mobility robustness optimization and mobility load balancing, (Miami, FL, United States, 2010), pp. 1-5

8. A Awada, B Wegmann, D Rose, I Viering, A Klein, in Proc. IEEE VTC Spring. Towards self-organizing mobility robustness optimization in inter-RAT scenario, (Budapest, Hungary, 2011), pp. 1-5

9. LYi-Bing, G Chai-Hien, LC Feng, Reducing call routing cost for femtocells. IEEE Trans. Wirel. Commun. 9(7), 2302-2309 (2010)

10. K Kitagawa, T Komine, T Yamamoto, S Konishi, in Proc. IEEE PIMRC. A handover optimization algorithm with mobility robustness for LTE systems, (Toronto, ON, Canada, 2011), pp. 1647-1651

11. D López-Pérez, A Valcarce, Á Ladányi, G de la Roche, J Zhang, Intracell handover for interference and handover mitigation in OFDMA two-tier macrocell-femtocell networks. EURASIP J. Wirel. Commun. Netw. 2010, $1-15(2010)$

12. YJ Kwon, DH Cho, in Proc. IEEE VTC Spring. Load based cell selection algorithm for faulted handover in indoor femtocell network, (Budapest, Hungary, 2011), pp. 1-5

13. Y Shen, T Luo, M Win, Neighboring cell search for LTE systems. IEEE Trans. Wirel. Commun. 11(3), 908-919 (2012) 
14. Z Fan, Y Sun, in Proc. IEEE VTC Spring. Access and handover management for femtocell systems, (Taipei, Taiwan, 2010), pp. 1-5

15. JM Moon, DH Cho, in Proc. IEEE WCNC. Novel handoff decision algorithm in hierarchical macro femto-cell networks, (Sydney, NSW, Australia, 2010), pp. 1-6

16. H Zhang, W Zheng, X Wen, C Jiang, in Proc. IEEE VTC Spring. Signalling overhead evaluation of HeNB mobility enhanced schemes in 3GPP LTE-Advanced, (Budapest, Hungary, 2011), pp. 1-5

17. H Zhang, W Ma, W Li, W Zheng, X Wen, C Jiang, in Proc. IEEE VTC Spring. Signalling cost evaluation of handover management schemes in LTE-Advanced femtocell, (Budapest, Hungary, 2011), pp. 1-5

18. J Flanagan, T Novosad, in Proc. IEEE VTC Fall, vol. 56. WCDMA network cost function minimization for soft handover optimization with variable user load, (Vancouver, BC, Canada, 2002), pp. 2224-2228

19. J Flanagan, T Novosad, in Proc. IEEE PIMRC, vol. 1. Maximizing WCDMA network packet traffic performance: multi-parameter optimization by gradient descent minimization of a cost function, (Beijing, China, 2003), pp. 311-315

20. 3GPP: E-UTRA and E-UTRAN overall description (December 2011)

21. 3GPP: E-UTRA and E-UTRAN overall description (June 2011)

22. M Kassar, B Kervella, G Pujolle, An overview of vertical handover decision strategies in heterogeneous wireless networks. Comput. Commun. 31(10), 2607-2620 (2008)

23. 3GPP: Evolved universal terrestrial radio access (E-UTRA); radio resource control (RRC) (2011)

24. DP Bertsekas, Nonlinear Programming. (Athena Scientific, Nashua, USA, 1999)

25. S Boyd, L Vandenberghe, Convex Optimization. (Cambridge University Press, Cambridge, United Kingdom, 2004)

26. P Jacquet, B Mans, G Rodolakis, in Proc. IEEE INFOCOM. Information propagation speed in mobile and delay tolerant networks, (Rio de Janeiro, Brazil, 2009), pp. 244-252

27. 3GPP: E-UTRA: further advancements for E-UTRA physical layer aspects (2010)

doi:10.1186/1687-1499-2013-27

Cite this article as: Zheng et al:: Mobility robustness optimization in selforganizing LTE femtocell networks. EURASIP Journal on Wireless Communications and Networking 2013 2013:27.

\section{Submit your manuscript to a SpringerOpen ${ }^{\mathcal{O}}$ journal and benefit from:}

- Convenient online submission

- Rigorous peer review

- Immediate publication on acceptance

- Open access: articles freely available online

- High visibility within the field

- Retaining the copyright to your article

Submit your next manuscript at $\boldsymbol{\wedge}$ springeropen.com 